\title{
Improving the soundscape quality of urban areas exposed to aircraft noise by adding moving water and vegetation
}

\author{
Martijn Lugten ${ }^{1}$, Merve Karacaoglu ${ }^{2}$, Kim White $^{3}$, Jian Kang ${ }^{4}$, Koen Steemers $^{1}$ \\ ${ }^{1}$ Martin Centre for Architectural and Urban Studies, University of Cambridge, 1 Scroope Terrace, Cambridge CB2 1PX, United Kingdom \\ ${ }^{2}$ Netherlands Aerospace Centre (NLR), Anthony Fokkerweg 9, Amsterdam 1059CM, the Netherlands \\ ${ }^{3}$ Department of Experimental and Applied Psychology, Vrije Universiteit Amsterdam, van der Boechorstraat 1, Amsterdam 1081BT, the \\ Netherlands \\ ${ }^{4}$ Institute for Environmental Design and Engineering, University College London, Central House, 14 Upper Woburn Place, London WC1H \\ ONN, United Kingdom
}

\subsection{Abstract}

Research shows that the sight of trees and the sound of moving water improve the soundscape quality of outdoor spaces exposed to road traffic noise. Effects are attributed to non-energetic masking, visual attentional distortion and congruence between sight and hearing. However, there is no literature on such effects for aircraft noise. Aircraft noise varies from other traffic sources, i.e. in terms temporal variability, duration and spectral composition, complicating the application of findings without further research. In a VR experiment reported in this article, participants were asked to rate scenarios with different sound levels of flyovers, urban typologies, vegetation and/ or water features. The results showed a significant improvement of the soundscape quality when 1) vegetation and 2) moving water were present, and especially when 3) vegetation and moving water were presented simultaneously, especially for residential areas in terms of the relative change. Moving water also reduced the saliency of aircraft flyovers significantly, changing the constellation of fore- and background sounds. Moving water raised the perceived audibility of the most dominant sound source too, which could be attributed to non-energetic masking effects. Our findings indicate that soundscape strategies can complement noise abatement in areas prone to aircraft noise.

\subsection{Introduction ${ }^{2}$}

Urban areas close to airports are exposed to aircraft noise which can result in annoyance and health complaints ${ }^{1,2}$. Over the last decades, a variety of interventions have been developed to limit sound exposure from road, rail and air traffic. The acoustic solutions range from quieter engines and airframes ${ }^{3}$ to noise barriers ${ }^{4}$, the design of urban blocks ${ }^{5}$ and building insulation schemes ${ }^{6}$. The

\footnotetext{
${ }^{1}$ mmcl2@cam.ac.uk/Martijn.Lugten@nlr.nl / corresponding author

${ }^{2}$ This section is identical to the 3.2.2. and 3.2.3. with the literature sections used for the introduction of the publication.
} 
effectiveness of these measures varies per case and per sound source, but mitigations like barriers and material properties become less effective when sound comes from above compared to sources close to the ground ${ }^{7,8}$. Because studies have shown that noise annoyance is also influenced by nonacoustic factors, e.g. noise sensitivity, attitudes, stress, trust in the authorities, fear, coping, time of the day, activities undertaken, perception of the source ${ }^{9,10}$, and by personality traits ${ }^{11,12}$, noise studies focus increasingly on the interaction between acoustic stimuli, receiver and context. In this respect, various studies point to the positive effects of natural scenes ${ }^{13}$ and the audio-visual interplay between moving water sounds and vegetation ${ }^{14,15}$, and the acoustic masking effect on the auditory appraisal of places exposed to road or railway noise ${ }^{16,17}$. This suggests traffic sounds are perceived as less annoying when water sounds are audible and foliage or vegetation are visible. However, for aircraft noise, these effects have not yet been explored. Aircraft noise differs from road or rail traffic in terms of spectral composition and the duration of a sound event ${ }^{18}$, position towards an observer, salience and attitude ${ }^{19,20}$. Because of these differences between aircraft and other traffic modalities, the question rises whether the presence of water and vegetation can equally improve the soundscape perception in areas exposed to aircraft noise. Sounds from moving water vary in temporal variability, loudness and sharpness, and can be artificial or natural ${ }^{21,22}$. A few listening-only studies reported sea waves as the most pleasantly rated water variety ${ }^{15,23}$, but sea sound is hard to implement in urban settings when designing for places that are not close to the coast. Water sounds do not improve the soundscape quality in all situations though ${ }^{21}$, and therefore the right source must be carefully designed and selected during implementation. For example, it was found that waterfalls or water features generating a relatively constant and low frequency sound were rated as less pleasant than babbling streams, which have a higher temporal variability ${ }^{14,21}$. Galbrun and $\mathrm{Ali}^{14}$ showed that, except for waterfalls with a high flow rate which generate higher levels of low frequency sound, the frequency response of water features and traffic sounds do not match. This means that the most preferred water features can mask traffic sounds in more ways than only obscuring the sound signal energetically. Sound masking techniques can be divided in two groups; 1) energetic, and 2) non-energetic or informational masking 24 refering to e.g. 25 . Energetic masking makes a target sound inaudible by adding sound with a similar spectral and power domain. In the second form of masking, the masking sound is (partially) different from the target sound, but creates uncertainty about the origin and meaning of the sound ${ }^{24,26}$. Therefore, it becomes harder to distinguish the target and masker sounds, increasing the audibility threshold of the individual sounds ${ }^{27}$. In urban contexts, masking is linked to the source prominence and ranking between fore- and background sounds, which make the soundscape of an area ${ }^{28}$. In other words, the saliency of sounds can be influenced by enhancing other sounds. Literature showed that adding moving water changed 
what people saw as the most prominent source for a soundscape, seen as a form of non-energetic masking by the authors ${ }^{29}$. Water can mask traffic noise energetically, but only when the sound spectrum and temporal variance of the two (or more) sources coincide ${ }^{14,22}$. Galbrun and Ali (2013) concluded that the frequency spectral components in road traffic make even the most preferred water varieties unsuitable for masking traffic noise energetically. Alternatively, studies suggest that added water can increase the auditory appraisal of road traffic noise by informational masking or distraction ${ }^{29,30}$. The sound level and spectral composition of added water features do not have to be equal to the traffic noise, but increase the soundscape quality when the water sound level is up to 3 $d B(A)$ lower than the noise level of the traffic noise ${ }^{14,30}$. A careful design of water features in public places could therefore improve the soundscape quality of urban environments contaminated with mechanical sounds.

Studies on the effects of vegetation on sound appraisal range from research on the impact of landscapes and surroundings ${ }^{31,32}$, to the role of trees and vegetation on walls ${ }^{13}$, fences and (noise) barriers ${ }^{33}$. Traditionally, projections and images combined with headphones or speakers were used, whereas now integral technologies like virtual reality (VR) have become more common ${ }^{16,34}$. Results from previous studies stress the importance of congruence between expectations and soundscape 31,35 and the positive effects of vegetation and natural visual cues in urban areas ${ }^{31}$. Also, it was found that the perception of noisiness decreases when a source remains partly visible through the greening ${ }^{33}$. More recently, studies have focused on the impact of green walls and trees in urban settings outdoors ${ }^{16,30}$, immersing participants in urban scenes by using projections or, more recently, virtual reality ${ }^{16,36}$. One finding was that vegetation, mainly in the form of trees, improved sound appraisal in an urban setting and scored better compared to other forms of vegetation like wall greening or shrubs ${ }^{30}$. Similar effects were found in a Belgian study where scenarios containing vegetation mounted on a fence over a motorway were most effective in improving the quality of the soundscape ${ }^{37}$. More importantly, in-situ studies show similar positive effects of visible green. In two separate studies, one in Belgium ${ }^{38}$ and one in Hong-Kong ${ }^{32}$, the sight of vegetation from within a dwelling decreased the level of self-reported noise annoyance by residents exposed to traffic noise. On a larger urban scale, vegetation and access to green areas (e.g. parks or nature) contribute to a lower annoyance rating from traffic noise ${ }^{12,39}$. This is not only attributed to the restorative character of green areas, but also to the aesthetic qualities of vegetation ${ }^{40-42}$. Van Renterghem ${ }^{13}$ showed that visible vegetation restores attenuation and provides stress relief, which reduces the negative effects of noise exposure. The psycho-acoustic effect of vegetation is estimated as the equivalent of a noise reduction of $10 \mathrm{~dB}(\mathrm{~A})$, and the effect is larger for higher sound exposure levels ${ }^{13}$. 
So, literature indicates the potential of moving water and visual vegetation to improve the perception of soundscapes. The question was, however, if moving water and the visibility of vegetation would improve the soundscape quality of civic areas exposed to aircraft noise. To the best of our knowledge, no information on this currently exists. Based on literature four hypotheses were formulated:

1. Visible vegetation in the form of trees is expected to improve the soundscape quality.

2. Moving water (water jets) is expected to improve the soundscape quality.

3. Visible vegetation and moving water combined would improve the soundscape quality even more than both interventions separately.

4. Moving water (water jets) diminishes the saliency and dominancy of aircraft flyovers.

This paper presents the results of a study examining these hypotheses.

\subsection{Methods}

\subsubsection{Participants}

Forty-one participants ( 32 females and 9 males, mean age 21.5 year, SD 2.5 year) took part in the experiment in a sound-attenuated laboratory room at the Vrije Universiteit Amsterdam. Data from two female participants were discarded after it turned out that nearly all their answers were marked as outliers when analysing the distribution of the data in Tukey boxplots. The research was carried out in Dutch with Dutch speaking participants only, all in good health and with good self-reported hearing. Participants were asked for written consent and the study was conducted in accordance with the norms of the Helsinki declaration ${ }^{43}$. This study was approved by the Psychology Ethics Committee of the University of Cambridge.

\subsubsection{Materials \\ 1.3.2.1. Conditions}

The study design was built upon four independent variables with two levels each: 1) urbanity (residential or commercial area), 2) aircraft flyovers (sound levels: 60 or $70 \mathrm{~dB}(\mathrm{~A})$ ), 3) vegetation (present or not present), 4) water features (fountain; present or not present). The combination of these four variables led to a total of sixteen conditions. Four samples without aircraft noise were added to move attention away from the flyovers and to ensure that participants would not focus on the aircraft alone. All scenarios were repeated twice, leading to a total of 40 scenarios. Participants were asked to fill out a questionnaire on a laptop after each scenario. Each of these variables is introduced in more detail below. 


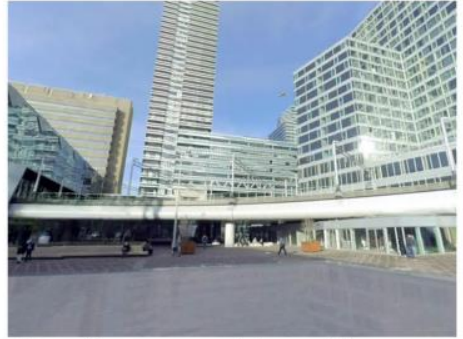

a) Baseline commercial area (c)

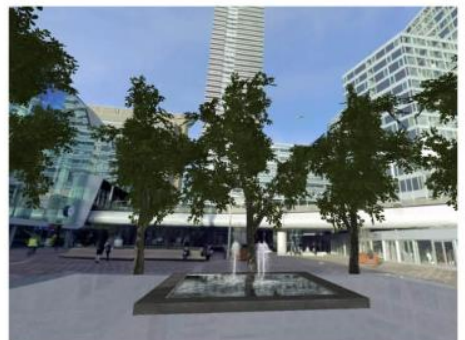

d) Com. + vegetation + fountain (cvf)

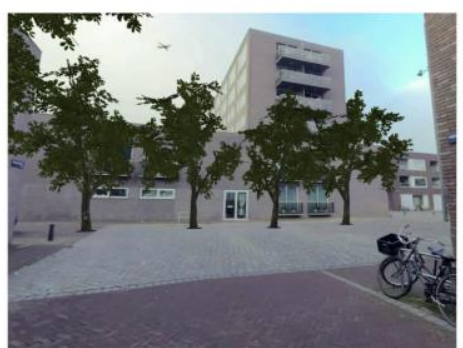

g) Residential area + vegetation (cv)

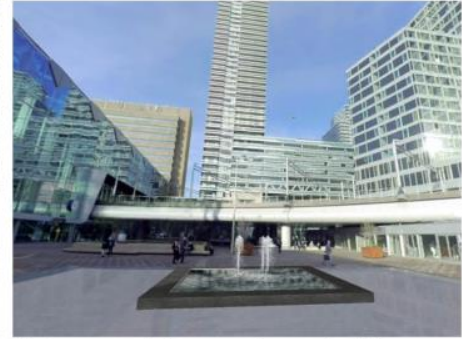

b) Commercial area + fountain (cf)

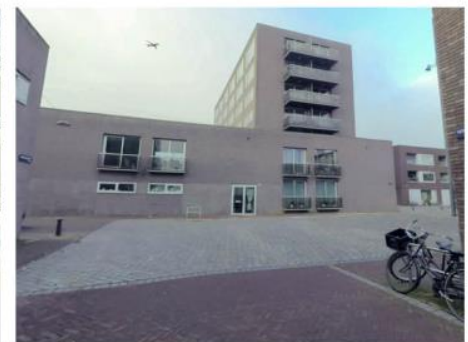

e) Baseline residential area ( $r$ )

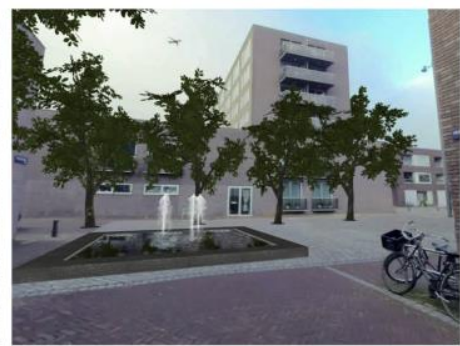

h) Res. + vegetation + fountain (rvf)

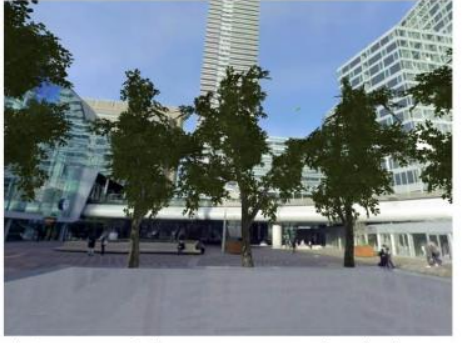

c) Commercial area + vegetation (cv)

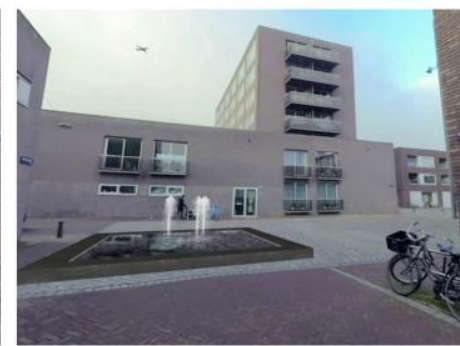

f) Residential area + fountain (rf)

Figure 1 Scenarios for commercial and residential areas which were combined with flyovers at 60 and 70 LAmax.

\subsubsection{Urbanity}

The baseline scenarios were filmed at two locations in the Netherlands, representing a commercial and a residential area. The commercial area (Figure 1, a-d) was a square located next to the central railway station in the city of Den Haag surrounded by shiny glass-clad high-rise buildings.

Pedestrians, cyclists, trams and vans rendered the scene vivid and dynamic. Footage for the residential site was shot in Amsterdam (Zeeburg district) (Figure 1, e-h) in a relative densely built-up urban area (built in the 2000s) with little human activity, albeit close to a playground (resulting in children's voices in the background). The requirement for both sites was that no vegetation would be visible from the position of the camera. Both sites were recorded with a $360^{\circ}$ camera formed by 8 GoPro Black edition (resolution 1440 p / 60 fps). The cameras were mounted on a sphere on top of a tripod (1.7 $\mathrm{m}$ high), to simulate eye-level. The individual frames were stitched together using Kolor autopano Video (KaV) software. Any visible vegetation, visually distracting pavement textures and street and railway signs were removed from the video, using Adobe Photoshop CC 2017 and Adobe Pro CC 2017. From the footage, clips with a duration of 55 seconds were cut and used as baseline scenarios, one clip for each location. The ambient sound was recorded with mono (Brüel \& Kjæl 
4189/2671) and binaural microphones (four-channel H2n). Recordings from the mono microphone were used to calibrate and set the sound level for the binaural samples. The microphones were placed directly underneath the sphere with the cameras. The maximum sound level in the excerpts was kept below $60 \mathrm{~dB}(\mathrm{~A})$ by muffling tonal pitches surpassing $60 \mathrm{~dB}(\mathrm{~A})$ using Audacity (version 2.1.3). Only in few cases, sharp tonal pitches from a passing tram in the commercial area were modified, as the researchers were afraid that a sharp sound from the wheels would be too distractive.

\subsubsection{Aircraft flyover}

For the aircraft flyover, a sample of a regular descending Airbus 330 aircraft (A330) at $2000 \mathrm{ft}(\approx 610$ m). from a previous study ${ }^{44}$ was used and calibrated for two $L_{\text {Amax }}$ values (60 dB(A) and $70 \mathrm{~dB}(A)$ ) (see Figure 2). The spectral composition, size, (visual) position and altitude of these flyovers used in this study were identical, in order not to introduce any extra variables. The flyover was clearly visible from the default direction of view.

The flights were modelled using the Netherlands Aerospace Centre's (NLR) Virtual Community Noise Simulator (VCNS) that generates a real-time virtual environment in which audio and visual signals are adjusted and synchronized with a head-mounted display and head-tracking headphones ${ }^{44,45}$. The sound signals were binaural and based on real-time audio rendering, creating an immersive stereo sound environment around the participant. Subjects could rotate $360^{\circ}$ degrees around the axis of the camera position but could not walk through the scenes. Studies show that a combination of videos and animations in the VCNS gives a realistic impression of an aircraft flyover ${ }^{46,47}$.

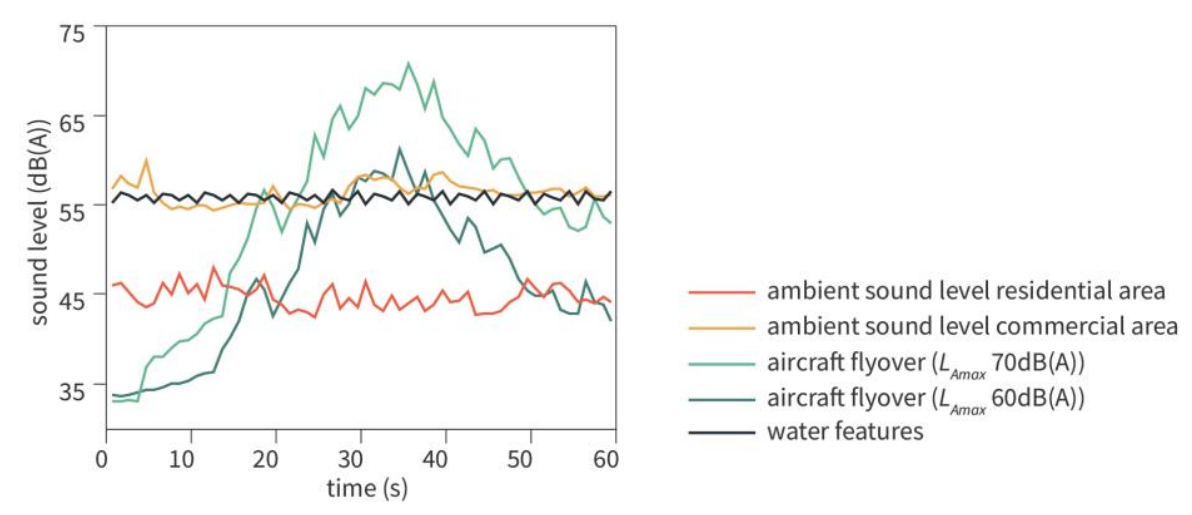

Figure 2 Sound level (in $d B(A))$ for sounds presented during the experiment: orange = aircraft flyover $\left(L_{A m a x} 70 d B(A)\right)$, dark blue $=$ fountain, grey $=$ ambient sounds commercial area, light blue $=$ aircraft flyover $\left(L_{\text {Amax }} 60 \mathrm{~dB}(A)\right)$, yellow $=$ ambient sounds residential area. 


\subsubsection{Vegetation}

Animations of birch trees were selected from a default library for Unity props and integrated with the videos. The appearance of the props was further adapted and transformed to match the videos as realistically as possible. Unity 3D game engine (version 5.4.1f1) was used to merge animation, flyovers and videos. The trees were placed in a circle around the stationary position of the camera, creating a visually permeable green canopy surrounding the participant. The trees (vegetation) covered an average surface of around 20 percent of the default view from eye-level based on analysis in Adobe Photoshop CS6.

\subsubsection{Water (fountain)}

The water variable comprised three fountain jets in the middle of a small rectangular pond, creating both a visual and acoustic effect. The visuals were selected from (default) Unity animated props while a binaural recording, derived from a study comparing various fountains for auditory quality ${ }^{21}$, was used for the acoustic component. The sound sample was rated as second-best in the soundscape pleasantness assessments by Rådsten-Ekman ${ }^{21}$, and represents a fountain formed by multiple jets with water falling down on water (pond or basin). The selected animation selected was carefully matched with the image of the fountain in the corresponding literature ${ }^{21}$. The fountain sound is characterized by its low variability and constant sound volume, which was calibrated at 57 $L_{\text {Amax }}$ like in the study by Rådsten-Ekman et al. ${ }^{21}$. The water sound was approximately $3 \mathrm{~dB}(\mathrm{~A})$ lower than the peak level of the quietest flyover (i.e., $60 \mathrm{~dB}(\mathrm{~A})$ ) in keeping with recommended settings for sound masking in relation to ambient noise in urban areas ${ }^{48}$.

\subsubsection{Apparatus}

The scenarios were presented to participants using Unity 3D game engine (version 5.4.1f1) on an Intel i5 6600 CPU with a Nvidia GTX-970 graphic card and head-mounted displays (HMD, Oculus Rift CV1, refresh rate $90 \mathrm{~Hz}$ ) and headphones (Bose QC 25). The headphones were calibrated with a dummy with two microphones at the position of the ears. The sound of the fountain was played, and the headphones and computer were adjusted to the right sound level.

\subsubsection{Questionnaire}

Because there are no standardized questionnaires for soundscape research (see e.g. ${ }^{16,34,49,50}$ ), let alone questionnaires for soundscape research using VR, a post-ante evaluation of questions and questionnaire was carried out.

The questionnaire consisted of three parts, with each one using questions from separate studies. Part one was formed of questions used in studies following the so-called 'Swedish Soundscape Quality Protocol'. Soundscape perception is measured on a quadrant scale with the opposites 
'pleasant versus unpleasant' and 'eventful versus uneventful' on both axes. A study by Axelsson, Nilsson and Berglund ${ }^{51}$ showed that these factors combined with 'familiarity' explain most variance of soundscape perception $(50,18$, and $6 \%$ respectively). Because of the predictive power of the opposites 'soundscape pleasantness versus unpleasantness' and 'soundscape eventfulness versus uneventfulness' for the perception of soundscape quality, these factors are frequently used to measure soundscape quality ${ }^{28,52}$. Soundscape pleasantness is generally attributed to natural sounds while soundscape eventfulness relates to the descriptions of liveliness and ambiance (e.g. the level of human sounds)(see e.g. ${ }^{29,51}$ ). The second part was formed by questions used in soundscape VRbased studies. In these studies, the perception of the auditory and visual components is tested separately, as well as the overall holistic perception. The third part consisted of questions about auditory attention and saliency to examine (non-energetic) masking effects used in soundscape research. The questions were previously used in in-situ studies to identify masking effects, e.g. of a fountain ${ }^{29}$, or to study auditory quality in relation to activity and context ${ }^{53}$.

The questions were translated from English to Dutch using standardized terms from previous soundscape studies in the Dutch language and the translations were kept as close as possible to the original question ${ }^{52}$.

\subsubsection{Pilot questionnaire}

The first part of the questionnaire asked participants to rate 1) the general quality of the scenario ('From a global point of view, how would you rate the environment that you just explored?'), 2) the general quality from a visual perspective ('From a visual point of view, how would you rate the environment that you just explored?') and 3) the general quality from an auditory perspective ('From an auditory point of view, how would you rate the environment that you just explored?') (see $\left.{ }^{50}\right)$. The second part of the questionnaire consisted of two questions related to the 4) pleasantness ('To what extent did you perceive the surrounding sound environment as pleasant in the environment that you just explored?') and 5) the eventfulness of the sound environment ('To what extent did you perceive the surrounding sound environment as eventful in the environment that you just explored?') (see ${ }^{51,52}$ ). Participants could rate each question on a linear scale between 0 and 10 (interval 1), ranging from (0) 'very bad' to (10) 'very good' for question 1-3, 'unpleasant' to 'pleasant' for question 4, 'uneventful' to 'eventful' for question 5. In the third part, participants were asked to write down the most prominent sound source heard in each scenario (Please name the sound source which you perceived as most prominent in the environment that you just explored) and to what extent this source dominated the soundscape (To what extent did you hear this sound in the environment just explored?). The first question was an open question while the second question asked participants to 
rate between the extremes 'did not hear at all' and 'dominated completely' between 0 and 10 (interval 1).

\subsubsection{Orthogonality of factors}

Table 1 results of repeated measures MANOVA Bonferroni post hoc tests

\begin{tabular}{|l|l|l|l|l|}
\hline & Question 2 & Question 3 & Question 4 & Question 5 \\
\hline Question 1 & $p=1.000$ & $p=1.000$ & $p=.162$ & $p<.001$ \\
\hline Question 2 & & $p=1.000$ & $p=.248$ & $p<.001$ \\
\hline Question 3 & & & $p=1.000$ & $p<.001$ \\
\hline Question 4 & & & & $p=.011$ \\
\hline
\end{tabular}

As the scenarios were presented twice, the mean score from the same two trials was calculated before analyses. Main effects and interactions between the conditions were studied by performing a Repeated Measures Multivariate Analysis of Variance (MANOVA) for the first five questions. In the MANOVA the orthogonality of the different factors tested per question was examined. Results showed that the first five questions were significantly different from each other $(F(4,190)=10.855, p$ $<0.001, r=0.23$ ), but a subsequent Bonferroni post-hoc test showed that only question 5 was significantly different from the other questions (see Table 1). This means that none of the metrics as asked in questions 1-4 (overall quality, overall visual quality, overall auditory quality and pleasantness) differed significantly from one another. This means that the composite of the four questions could be studied as a whole by adjusting the F-values or by including the factor 'question' as a between-subjects factor ${ }^{54}$. Consequently, if all four questions were to be taken together as one, the rigidity of the statistical test would increase, inflating the risk of a type II error. Based on these arguments, the decisions was made to disregard the first three questions and focus on the auditory pleasantness and eventfulness instead (i.e. question four and five), as the predictors of soundscape quality. Therefore, only questions 4-7 were used for further analysis.

\subsubsection{Procedure}

Upon arrival, participants signed the informed consent, after which they were led into a soundattenuated room where the head-mounted display and headphones were fitted. To optimize immersion in the virtual scenes and to avoid a focus on auditive stimuli only, participants were asked to experience each scenario as if they were passing by this area and decided to pause for a moment. Also, they were told that the locations were situated in a metropolitan area (containing commercial and residential sites), wherein traffic (including cars, trams, trains and aircraft), people and amenities surrounded the scenes. Participants began the experiment with a practice session in which they passively experienced baseline scenarios from the two areas from a standing position. Once they were adjusted to the VR-setting, the actual experiment commenced with presentations of 
the conditions in random order, controlled by the experimenter present in the room. The total duration of the experiment varied between 90 and 120 minutes per candidate. Participants were allowed to take a small pause after each scenario without leaving the sound-attenuated room.

\subsection{Results}

\subsubsection{Soundscape quality}

For the data analyses, only results from scenarios containing aircraft flyovers were included. The results of these sixteen scenarios were analysed by means of a repeated measures ANOVA design for the two relevant questions for soundscape quality. The two predictors for soundscape quality, auditory pleasantness and eventfulness, are presented and discussed together. The results for the three interventions are presented one by one.

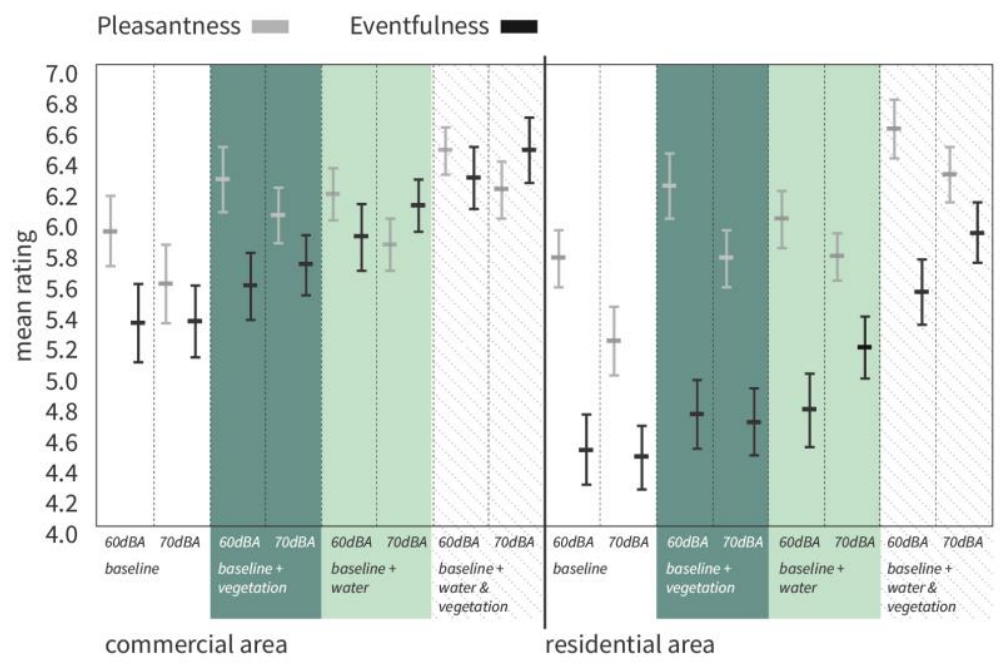

Figure 3 Mean ratings and standard error of the mean (+/-SEM) for soundscape pleasantness and eventfulness ratings per scenario (see Figure 1); split according to location (commercial area on the left-hand side, residential area on the righthand side), and grouped per intervention (none, vegetation, water, vegetation and water combined). 
Table 2 Percentage change of mean ratings of scenarios with vegetation, water, combination of water and vegetation compared to the baseline scenarios (water / vegetation absent, $60 \mathrm{~dB}(A)$ and $70 \mathrm{~dB}(A)$ ) for soundscape pleasantness and eventfulness

\begin{tabular}{|c|c|c|c|c|c|c|c|c|c|c|c|c|}
\hline \multirow{3}{*}{$\begin{array}{l}\text { Change } \\
\text { in \% } \\
L_{\text {Amax }} \text { in } \\
d B(A)\end{array}$} & \multicolumn{6}{|c|}{ Commercial area } & \multicolumn{6}{|c|}{ Residential area } \\
\hline & \multicolumn{2}{|c|}{ Vegetation } & \multicolumn{2}{|l|}{ Water } & \multicolumn{2}{|c|}{ Combined } & \multicolumn{2}{|c|}{ Vegetation } & \multicolumn{2}{|c|}{ Water } & \multicolumn{2}{|c|}{ Combined } \\
\hline & 60 & 70 & 60 & 70 & 60 & 70 & 60 & 70 & 60 & 70 & 60 & 70 \\
\hline $\begin{array}{l}\text { Pleasant- } \\
\text { ness }\end{array}$ & +5.6 & +8.0 & +6.9 & +7.6 & +11.7 & +11.0 & +8.3 & +10.3 & +4.5 & +10.6 & +14.7 & +20.9 \\
\hline $\begin{array}{l}\text { Eventful- } \\
\text { ness }\end{array}$ & +4.6 & +7.0 & +10.6 & +14.2 & +17.8 & +20.9 & +5.1 & +5.2 & +5.7 & +16.1 & +22.8 & +32.9 \\
\hline
\end{tabular}
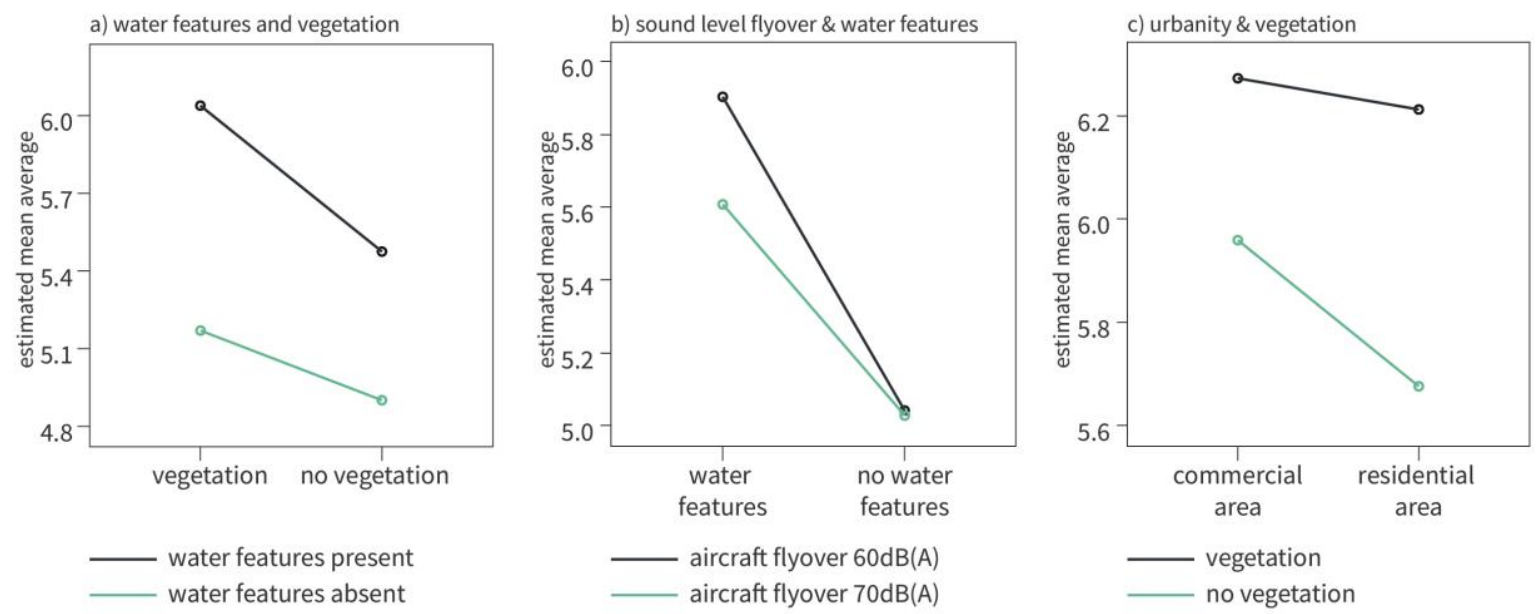

Figure 4 Estimated marginal means for the interactions between a) eventfulness scores for water features and vegetation, $b$ ) eventfulness scores for the sound level of the aircraft flyover and water features and c) pleasantness scores for urbanity versus vegetation

\subsubsection{Vegetation}

A main effect of vegetation was found for both predictors of soundscape quality (auditory pleasantness; $(F(1,38)=52.54, p<0.001, r=0.76)$, and eventfulness $(F(1,38)=37.12, p<0.001, r=$ $0.70)$ ). The results show that the presence of vegetation led to higher ratings for both indicators. The direction of the main effect is visible in Figure 3. The figure shows that the absolute change in scores was higher for the residential area compared to the commercial site. This effect can be also observed in Table 2, which represents the percentage of change in the ratings of scenarios with the interventions compared to the baseline scenarios. The mean ratings for soundscape pleasantness increased by approximately $7 \%$ for the commercial area and $9 \%$ for the residential area when vegetation was present. In the same way, eventfulness ratings increased by $6 \%$ and $5 \%$ for the commercial and residential areas respectively when vegetation was visible. An interaction between 
urbanity and vegetation was found $(F(1,38)=4.64, p=0.038, r=0.33)$ for soundscape pleasantness, see Figure 4. The graph shows that the soundscape was perceived as more pleasant in both areas where vegetation was present. However, the difference between the absence and presence of vegetation on the soundscape pleasantness was greater in the residential areas than in the commercial area. This suggests that vegetation as a strategy to improve the soundscape pleasantness is especially effective around dwellings. The results show that the presence of vegetation improved both the soundscape pleasantness and eventfulness compared to the baseline scenarios, with larger improvement observed for the scenarios containing the loudest aircraft flyover $(70 \mathrm{~dB}(\mathrm{~A}))$ and for the residential area.

\subsubsection{Moving water}

As with vegetation, the presence of water features had a positive effect on both the pleasantness and eventfulness ratings of the soundscape. The analyses showed that water was a main effect for both soundscape quality predictors (auditory pleasantness; $(F(1,38)=4.57, p=0.039, r=0.33$ ), and eventfulness; $(F(1,38)=31.22, p=0.001, r=0.67)$. Table 2 and Figure 3 show that with the presence of moving water, mean ratings for the soundscape pleasantness increased by $7 \%$ in the commercial area and $8 \%$ for the residential area. For the soundscape eventfulness, mean ratings increased by $12 \%$ and $11 \%$ for the commercial and residential area respectively. Again, the percentage increase for scenarios with moving water compared to the basis scenarios was larger for $70 \mathrm{~dB}(\mathrm{~A})$ than for $60 \mathrm{~dB}(\mathrm{~A})$ flyovers. Moreover, the analysis revealed a significant interaction between water features and the sound level of the flyover $(F(1,38)=5.19, p=0.028, r=0.35)$ (see Figure $4 b)$. When water features were absent, the sound level of the flyover did not affect the perceived eventfulness of the soundscape. However, when water features were present, the perceived eventfulness of the soundscape was higher for both flyovers, especially for the loudest flyover used in the experiment $\left(70 \mathrm{~dB}(\mathrm{~A}) L_{\operatorname{Amax}}\right)$. This could be related to the timespan during which the sound level of the fountains obscures that of the flyover (see Figure 2), which is shorter for a flyover with a $L_{A \max }$ of $70 \mathrm{~dB}(\mathrm{~A})$ (see e.g. $\left.{ }^{55,56}\right)$.

\subsubsection{Combined effects}

Compared to scenarios featuring either water features or vegetation, mean ratings for scenarios combining both interventions were higher for both soundscape pleasantness and eventfulness (see Figure 3 and Table 2). The scores for soundscape pleasantness increased by $11 \%$ and $18 \%$ for the commercial area and residential area respectively. For soundscape eventfulness, these scores increased by $19 \%$ and $28 \%$ for the commercial and residential areas compared to the baseline scenarios. The eventfulness ratings where higher for the $70 \mathrm{~dB}(A)$ than for the $60 \mathrm{~dB}(A)$ aircraft flyovers, especially for the residential area. The ANOVA revealed that the interaction between water 
and vegetation was only significant for soundscape eventfulness $(F(1,38)=6.49, p=0.015, r=0.38)$ (see Figure 4a). This interaction shows that although the vegetation did not change the sound signal, together with water features it made the participants perceive the soundscape as more eventful than could be accounted for by both factors individually. A similar interaction was not found for soundscape pleasantness.

\subsubsection{Non-energetic masking effects \\ 1.4.2.1. Source dominancy}

For the last two questions participants were asked to write down the most prominent sound source heard per scenario and to rate the audibility of this sound source. The objective of these questions was to investigate the effect of vegetation and water on auditory masking. As each scenario was repeated twice, participants answered the question twice per scenario. Because the answers were categorical, it was not possible to average the results. Therefore, all answers were included in the data analyses meaning that $78(39 \times 2)$ possibilities per scenario were evaluated. In a few cases (20/1248; 1.6\%), participants indicated two sound sources simultaneously. In these cases, only the first answer was selected for further analyses. This ensures that the combined size of data in the groups is similar before and after an intervention, which is required for the statistical analyses.

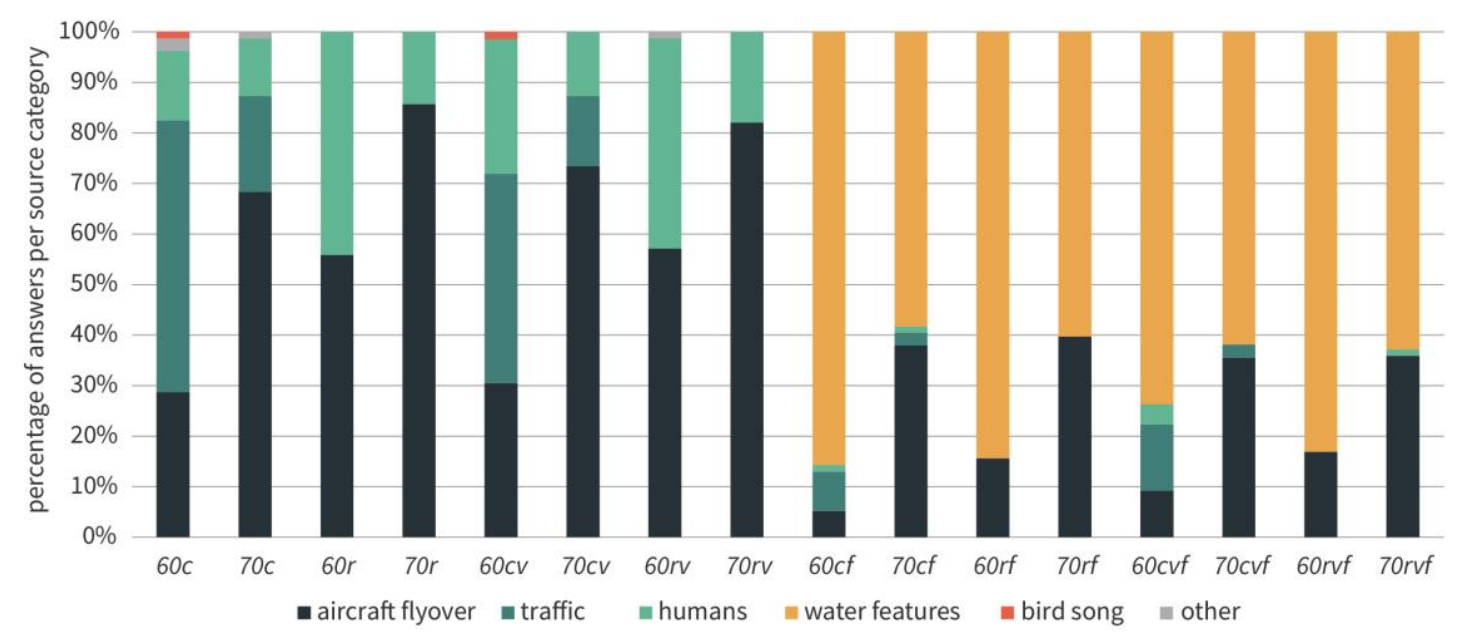

Figure 5 Percentage of participant answers per scenario for the most prevalent sound, corresponding to one of the six sound source categories (aircraft, other traffic, human sounds, fountain, bird song, undefined)

Figure 5 shows the distribution of the answers per scenario. The congruence between answers given between the first and second time scenarios were shown can also be seen. Answers from the open question were clustered into six categories; aircraft flyover ((faltering) aircraft, aircraft engines), traffic (trams, cars, metro, trains, vans), humans ((playing) child(ren), footsteps, high heels, people talking, voices, people (passing)), water features (fountain(s), pond), natural sounds (wind, bird song), other (rustling/sighing (i.e. suizen in Dutch)). Participants reported answers falling in one of Journal of the Acoustical Society of Acoustics, 2018, vol. 144, p. 2906-2917 
the last two categories in only 4 cases ( $0.3 \%$ of all answers given). The graph shows that for scenarios without any water features, aircraft, traffic and human sounds were most prominent in the soundscape. The graph suggests a shift from aircraft and traffic sounds to water features as the most prominent sound source when fountains were present.

It was also observed that there was no effect of vegetation on the most prominent sound source reported by participants, nor that vegetation and water combined led to different answers. These

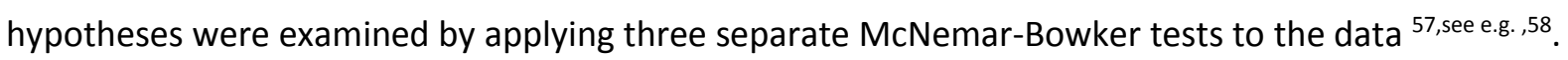
This test was chosen because the data is categorical and not independent (repeated measures design), for which reason methods such as Pearson's chi-square or multinomial logistic regression are not applicable. McNemar-Bowker tests for the symmetry of a contingency table while additional Bonferroni tests were used to study the direction of change ${ }^{58}$. This means that the symmetry between two groups is analyzed to study groups differ. To meet the assumption for the McNemarBowker test, the categories 'water features', 'natural sounds' and 'other' were merged into one category called 'natural features'. When water features were present, all answers in this merged category were attributed to the factor 'water features' and none to the categories of 'natural sounds' or 'other'. To test for the effect of water features, all scenarios were combined and divided into two groups; scenarios 1) with and 2) without the presence of water features. The change in answers given by a participant for comparable scenarios falling into the first and second category were compared. The same procedure was repeated for vegetation, and the effect of vegetation when water was present too.

Table 3 Results of the separate McNeman-Bowker tests

\begin{tabular}{|c|c|c|}
\hline Absence vs presence of water features (total) & $\chi^{2}=452.83$ & $p<.001$ \\
\hline $\begin{array}{c}\text { Absence vs presence of vegetation (when water } \\
\text { is present) }\end{array}$ & $\chi^{2}=4.07$ & $p=.539$ \\
\hline $\begin{array}{c}\text { Absence vs presence of vegetation (when water } \\
\text { is absent) }\end{array}$ & $\chi^{2}=5.83$ & $p=.442$ \\
\hline
\end{tabular}

Table 3 shows the results from the three McNemar-Bowker tests; only the asymmetry between scenarios with- and without water was significant. Vegetation or the vegetation combined with water did not result in significant asymmetries. This means that the choice of the most prominent sound source was significantly different when water features were present, but not when vegetation was visible. An additional Bonferroni post hoc test was carried out to determine what sources caused the asymmetry between scenarios with- and without water features. Four significant effects were found: between aircraft and humans $(p=0.012)$, between aircraft and water features $(p<$ 
$0.001)$, traffic and water features $(p<0.001)$ and humans and water features $(p<0.001)$. So, the results show that if participants had selected aircraft, traffic or humans as the most prominent sound sources in scenarios without water features, they tended to select water features and humans as the most prominent sound sources for the same scenarios containing water features.

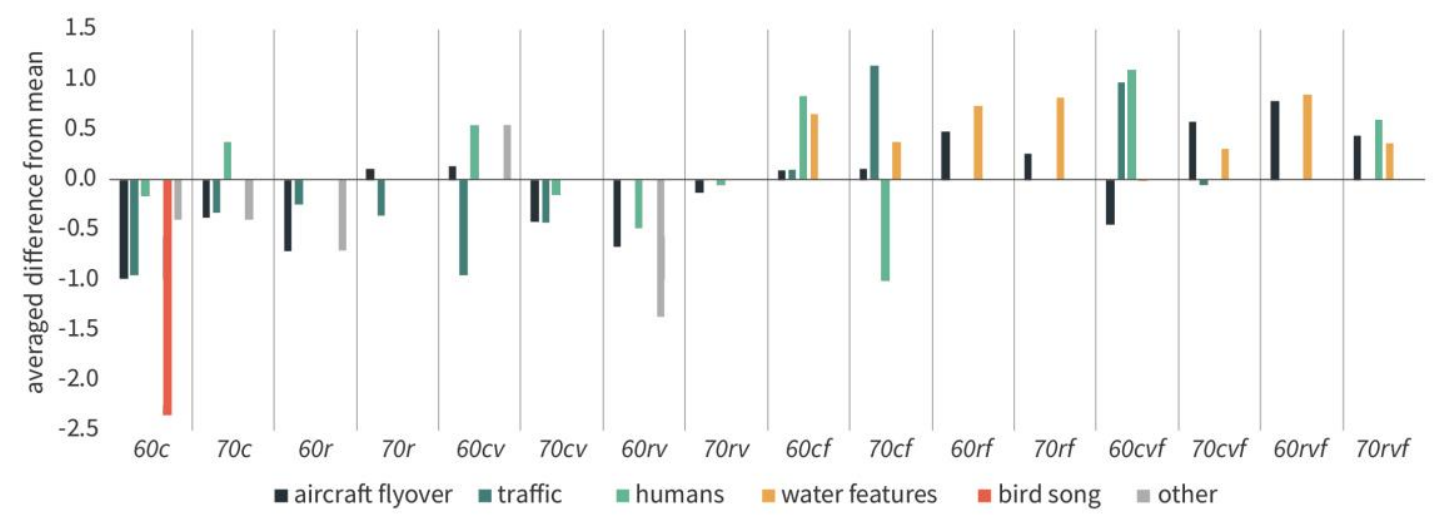

Figure 6. Averaged differences from each participant's mean score for the audibility of the most prominent sound source per scenario. The averaged difference is plotted from the mean per source category and per scenario.

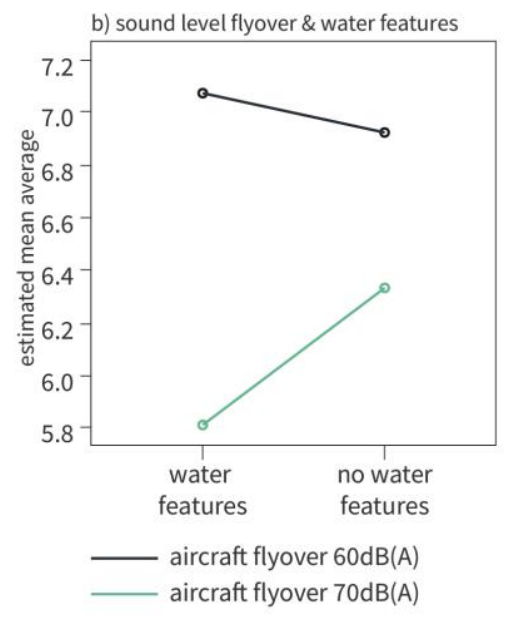

Figure 7. Interaction effect between water features and sound level of the flyover found for the audibility of the most prominent sound source

\subsubsection{Audibility of prominent sound sources}

In the last question, participants were asked to rate the audibility of the most prominent sound source on a 10-point scale between 0 ('did not hear at all') and 10 ('dominated completely'). The data was analyzed using a repeated-measures ANOVA based on the average audibility score per scenario. These average scores were independent of the source to which these scores were attributed. The ANOVA revealed main effects for the sound level of the aircraft $(F(1,38)=4.67, p=$ 0.04, $r=0.33)$, urbanity $(F(1,38)=13.01, p<0.001, r=0.51)$ and water features $(F(1,38)=39.06, p<$ $0.001, r=0.71)$. Also, the analysis showed an interaction effect between the sound level of the 
flyover and water features $(F(1,38)=21.49, p<0.001, r=0.60)$ (see Figure 7$)$. This means that the audibility of the most prominent sound source increased when water was present, but this effect was greater when the sound level of the aircraft was low $(60 \mathrm{~dB}(\mathrm{~A}))$.

A shortcoming of the ANOVA is that it only revealed the within-subject change in audibility scores, without analyzing differences between individually selected sound sources. For example, what would happen to the audibility scores of e.g. aircraft if participants selected sound sources other than water in scenarios containing water features, and would the audibility score of such sources increase, decrease or remain unchanged compared to scenarios without fountains? Although the study focused on the effect of water features on the audibility scores of aircraft noise in the first place, all possible sound sources were evaluated.

In a second explorative analysis, the audibility scores per category of the most prominent sound source were studied. Because the absolute ratings on the eleven-point scale may vary between participants, it was decided to focus on the relative within-subject (W-S from now on) change per scenario. This makes it possible to study the relative change between the 32 scenarios clustered for each sound category. For instance, if people selected 'aircraft' or 'traffic' as the most prominent source for comparable scenarios with- and without water features, the expectation was to find similar audibility scores. The average audibility scores for both scenarios would then be similar for this person. The scores for the relative W-S change of the audibility scores per source category where calculated by the following equations.

$$
\begin{gathered}
\mu_{\text {person }}=\frac{1}{32} \sum_{i=1}^{32} x_{i} \\
\mu_{\text {category }}=\frac{1}{n_{\text {category }}} \sum_{i=1}^{n_{\text {category }}}\left(x_{i}-\mu_{\text {person }}\right)
\end{gathered}
$$

First, the participant's mean audibility score $\left(\mu_{\text {person }}\right)$ was calculated by including the scores of all the possible 32 answers $\left(x_{i}\right)$. For each of the 32 individual scores, the mean average was subtracted from the individual score $\left(x_{i}-\mu_{\text {person }}\right)$. This results in the relative difference between the scores attributed to the 32 scenarios. Because the relative scores are linked to the categories of question 6 , it is possible to determine the sound source behind the 32 relative scores. In the last step the average scores per source $\mu_{\text {category }}$ were calculated based on the combined scores of the participants that selected the same source $\left(n_{\text {category }}\right)$. Figure 6 plots the relative difference in audibility scores per scenario and for the sources participants had indicated, divided in six source categories. The audibility of water features, when selected as the most prominent sound source, was 
clearly higher than other sound sources. However, even when participants selected other sound sources than water features as the most prominent sound source in scenarios containing water features, in most cases, the audibility scores for these sources were higher than for the same scenarios without water features. This suggests that the presence of water features increased the audibility of the prominent sound source in general, or gave people the impression that the prominent sound source of their choice was more audible. However, as this observation is based on a small sample size, caution is needed in respect to the interpretation of this finding.

\subsection{Discussion}

This article presented the results of a VR laboratory experiment studying the effects of vegetation and water features on the soundscape perception of areas exposed to aircraft noise. Firstly, the results of the study show that vegetation and water features led to an improvement in the soundscape quality in terms of higher pleasantness and eventfulness ratings. However, as shown in Figure 3 and Table 2, the ratings and effects differ per location and for the sound level of the flyover. For example, the pleasantness ratings for moving water and vegetation are lower for aircraft flyovers with a peak level of $70 \mathrm{~dB}(\mathrm{~A})$. Nonetheless, the effect as measured in percentage change of the soundscape ratings is largest for the loudest flyover in this study. A similar effect was observed for the difference between the two locations. Here, the absolute ratings were lower for the residential area, but the improvement in the soundscape quality as measured by the percentage change of pleasantness and eventfulness ratings was comparable for both sites.

Similar effects of moving water, vegetation and a combination of the two were found in previous studies on soundscape quality and (road) traffic sources see e.g.,16,30. However, in comparison to earlier studies, the effect size of the interventions (vegetation, water, combined) is smaller or similar, which can be attributed to various factors. For example, studies vary in the choice of research methodologies, metrics, selection of location(s), (average) sound levels and cultural backgrounds. The variations complicate to comparison of the results of this article with earlier work. Moreover, vegetation in urban settings does not indicate that more trees automatically improve the soundscape quality. Instead, visual and auditory expectations have to be in harmony, which means that trees in an urban setting are different than trees in a forest ${ }^{31,35}$. Additionally, the results do not disclose to what extent the source should be visible or screened. Literature suggests that a higher level of visual screening led to a higher noisiness rating ${ }^{33}$. Aircraft noise might have an even stronger effect, as general attitude towards aircraft is, among other factors, related to safety concerns associated with e.g. the probability of a crash ${ }^{20,59}$. Visibility and being able to see the aircraft may evoke a sense of control, thereby possibly improving the soundscape perception. However, more 
research will be needed to study this effect. The same applies for water features, as the study combined the visual design of the fountain and sound level of the water jets. The question remains as to what would happen if the sound level was louder or quieter. Also, was it the auditory sensation that rendered the positive response or did the visual qualities of the fountain also play a role? Similar questions remained after a previous in-situ study where the water sound of a fountain, in itself, had no effect on the soundscape perception of a park ${ }^{29}$. In other words, although the overall soundscape quality improved when the fountain was switched on, the water sound had no significant effect on the soundscape quality. Instead, it was suggested that the water sound improved the soundscape indirectly, because it reduced the audibility of traffic. The researchers attributed this effect to auditory masking effects diminishing the attention and audibility of the traffic sounds.

A third observation was that the presence of water features influenced the ranking of sound sources in terms of auditory dominancy. Aircraft and general traffic sounds seem to have been reduced in saliency and dominancy, pointing to a change in the constellation of fore- and background sounds. The presence of moving water did not only change which sources were indicated as most prominent, but also increased the perceived audibility of these sources. The results showed a significant increase in the audibility scores in the presences of water features. Results from an additional explorative analysis showed that the audibility of almost any source, if indicated as the most prominent source, increased when water features were present. This was a somewhat surprising outcome and suggests that moving water seems to act as an acoustic filter or masker, limiting the sources' audible. In other words, participants who selected sounds other than moving water, although it was present, seemed to hear these sounds more clearly because the water sound subdues the signals of quieter sounds. In fact, this reduces the range of sounds to choose from. Based on literature, this might be linked to non-energetic or informational masking ${ }^{26,27}$. In this context, masking is seen the auditory similarity between target and masking stimuli, creating uncertainty about the origin and masker sound(s) and a competitive selection process ${ }^{27,60}$. The acoustic signal is confused with the sound maskers, i.e. moving water, which can suppress audibility and distort and change focus and saliency ${ }^{26,61}$. The results suggest that, for most scenarios, water features overshadowed aircraft and traffic sounds in saliency. From a theoretical perspective, adding a masking sound can mean that the threshold to hear other sound sources increases, which mean that quieter sounds are not clearly distinguishable any longer ${ }^{26}$. The results suggest a similar response during this experiment, e.g. the formation of a hearing threshold emphasizing specific sounds, attentional distortion and competition. However, as the sample size was small, more 
research on these individual aspects is needed, e.g. acoustic 'amalgamation' of frequency spectrums and informational masking in relation to complex visual environments.

\subsection{Conclusions}

Based on the results and discussion, the following conclusions can be drawn about the individual and combined effects of moving water and vegetation on the soundscape quality of residential and commercial areas exposed to aircraft noise varying in loudness. Both moving water and vegetation led to a significant improvement of the soundscape quality defined as the pleasantness and eventfulness of the soundscape:

- Compared to the baseline scenarios without vegetation and water features, the relative improvement of the soundscape quality that can be attributed to moving water and vegetation are largest for flyovers with a $L_{A \max }$ of $70 \mathrm{~dB}(\mathrm{~A})$ compared to $60 \mathrm{~dB}(\mathrm{~A})$. On average, soundscape ratings, i.e. the averaged scores of soundscape pleasantness and eventfulness combined, were respectively $6 \%(60 \mathrm{~dB}(\mathrm{~A}))$ and $10 \%(70 \mathrm{~dB}(\mathrm{~A}))$ higher when either moving water or vegetation was present.

- On average, the eventfulness of the soundscapes increased by $20 \%(60 \mathrm{~dB}(\mathrm{~A}))$ and $26 \%$ (70 $d B(A))$ respectively, for scenarios with both vegetation and moving water. Average pleasantness scores increased by $13 \%(60 \mathrm{~dB}(\mathrm{~A}))$ and $16 \%(70 \mathrm{~dB}(\mathrm{~A}))$ respectively.

- When present, moving water was more salient than other sound sources. Also, moving water had a significant effect on the order of what was denoted as the most dominant sound source. For instance, on average, moving water was perceived as a more dominant sound source than aircraft and other traffic sound sources, changing the order of fore- and background sounds.

- The presence of moving water led to an increase in the audibility score of the most prominent sound source per scenario. Further analyses of the data suggest that the audibility scores for all sound sources increase, regardless of the category. This may be attributed to aspects of informational masking and an acoustic filter, or hearing threshold evoked by the sound of water.

- A MANOVA analysis showed that the metrics used to measure the overall quality, visual quality, auditory quality and auditory pleasantness are not orthogonal and thereby independent. This is especially important when virtual reality is used to carry out soundscape research.

The results of the study show that soundscape interventions like moving water and vegetation can contribute to a better perceptual quality of areas exposed to aircraft noise. Implementing such 
interventions can complement noise abatement strategies used by urban design practitioners. The results also open new avenues for future research, especially on the in-situ application of water and vegetation, and also on auditory masking effects. 


\subsection{References}

1. Haines, M. M., Stansfeld, S. a, Job, R. F., Berglund, B. \& Head, J. Chronic aircraft noise exposure, stress responses, mental health and cognitive performance in school children. Psychol. Med. 31, 265-277 (2001).

2. Franssen, E. A. M., Van Wiechen, C. M. A. G., Nagelkerke, N. J. D. \& Lebret, E. Aircraft noise around a large international airport and its impact on general health and medication use. Occup. Environ. Med. 61, 405-413 (2004).

3. Netjasov, F. Contemporary measures for noise reduction in airport surroundings. Appl. Acoust. 73, 1076-1085 (2012).

4. Muradali, A. \& Fyfe, K. R. Accurate barrier modeling in the presence of atmospheric effects. Appl. Acoust. (1999). doi:10.1016/S0003-682X(98)00023-1

5. Echevarria Sanchez, G. M., Van Renterghem, T., Thomas, P. \& Botteldooren, D. The effect of street canyon design on traffic noise exposure along roads. Build. Environ. 97, 96-110 (2016).

6. ICAO. ICAO Environmental Report 2013. ICAO Environ. Rep. 2013 1-224 (2013).

7. Donavan, P. R. Model study of the propagation of sound from V/STOL aircraft into urban environments. (MIT, 1973).

8. Ismail, M. \& Oldham, D. The effect of the urban street canyon on the noise from low flying aircraft. Build. Acoust. 9, 233-251 (2002).

9. Kroesen, M., Molin, E. J. E. \& van Wee, B. Testing a theory of aircraft noise annoyance: A structural equation analysis. J. Acoust. Soc. Am. 123, 4250-4260 (2008).

10. Maris, E., Stallen, P. J., Vermunt, R. \& Steensma, H. Noise within the social context: Annoyance reduction through fair procedures. J. Acoust. Soc. Am. 121, 2000 (2007).

11. Bartels, S., Márki, F. \& Müller, U. The influence of acoustical and non-acoustical factors on short-term annoyance due to aircraft noise in the field - The COSMA study. Sci. Total Environ. 538, 834-843 (2015).

12. Li, H. N., Chau, C. K. \& Tang, S. K. Can surrounding greenery reduce noise annoyance at home? Sci. Total Environ. (2010). doi:10.1016/j.scitotenv.2010.06.025

13. Van Renterghem, T. Towards explaining the positive effect of vegetation on the perception of environmental noise. Urban For. Urban Green. (2018). doi:10.1016/j.ufug.2018.03.007

14. Galbrun, L. \& Ali, T. T. Acoustical and perceptual assessment of water sounds and their use over road traffic noise. J. Acoust. Soc. Am. 133, 227 (2013).

15. Rådsten-Ekman, M., Axelsson, Ö. \& Nilsson, M. E. Effects of sounds from water on perception of acoustic environments dominated by road-traffic noise. Acta Acust. united with Acust. 99, 218-225 (2013).

16. Echevarria Sanchez, G. M., Van Renterghem, T., Sun, K., De Coensel, B. \& Botteldooren, D. Using Virtual Reality for assessing the role of noise in the audio-visual design of an urban public space. Landsc. Urban Plan. 167, 98-107 (2017).

17. Jeon, J. Y., Lee, P. J., You, J. \& Kang, J. Acoustical characteristics of water sounds for soundscape enhancement in urban open spaces. J. Acoust. Soc. Am. 131, 2101-2109 (2012).

18. Zaporozhets, O., Tokarev, V. \& Attenborough, K. Aircraft Noise: Assessment, Prediction and Control. (Taylor \& Francis, 2011).

19. Babisch, W. et al. Annoyance due to aircraft noise has increased over the years-Results of the HYENA study. Environ. Int. 35, 1169-1176 (2009).

20. Kroesen, M. \& Schreckenberg, D. A measurement model for general noise reaction in response to aircraft noise. J. Acoust. Soc. Am. 129, 200-210 (2011).

21. Rådsten-Ekman, M., Lundén, P. \& Nilsson, M. E. Similarity and pleasantness assessments of water-fountain sounds recorded in urban public spaces. J. Acoust. Soc. Am. 138, 3043-3052 (2015).

22. Watts, G. R., Pheasant, R. J., Horoshenkov, K. V. \& Ragonesi, L. Measurement and subjective assessment of water generated sounds. Acta Acust. united with Acust. 95, 1032-1039 (2009).

23. Bolin, K., Nilsson, M. E. \& Khan, S. The potential of natural sounds to mask wind turbine noise. Acta Acust. united with Acust. 96, 131-137 (2010).

24. Durlach, N. Auditory masking: Need for improved conceptual structure. J. Acoust. Soc. Am. 120, 1787-1790 (2006).

25. Watson, C. Uncertainty, informational masking, and the capacity of immediate auditory memory. in Auditory processing of complex sounds (eds. Getty, D. \& Howard, J.) 267-277 (1987).

26. Durlach, N. I. et al. Note on informational masking. J. Acoust. Soc. Am. 113, 2984-2987 (2003).

27. Watson, C. S. Some comments on informational masking. Acta Acust. united with Acust. 91, 502-512 (2005).

28. Andringa, T. C. \& Lanser, J. J. L. How pleasant sounds promote and annoying sounds impede health: A cognitive approach. Int. J. Environ. Res. Public Health 10, 1439-1461 (2013).

29. Axelsson, Ö., Nilsson, M. E., Hellström, B. \& Lundén, P. A field experiment on the impact of sounds from a jet-andbasin fountain on soundscape quality in an urban park. Landsc. Urban Plan. 123, 46-60 (2014).

30. Hong, J. Y. \& Jeon, J. Y. Designing sound and visual components for enhancement of urban soundscapes. J. Acoust. Soc. Am. 134, 2026-2036 (2013).

31. Viollon, S., Lavandier, C. \& Drake, C. Influence of visual setting on sound ratings in an urban environment. Appl. Acoust. 63, 493-511 (2002). 
32. Leung, T. M., Xu, J. M., Chau, C. K., Tang, S. K. \& Pun-Cheng, L. S. C. The effects of neighborhood views containing multiple environmental features on road traffic noise perception at dwellings. J. Acoust. Soc. Am. 141, 2399-2407 (2017).

33. Watts, G., Chinn, L. \& Godfrey, N. The effects of vegetation on the perception of traffic noise. Appl. Acoust. 56, 3956 (1999).

34. Ruotolo, F. et al. Immersive virtual reality and environmental noise assessment: An innovative audio-visual approach. Environ. Impact Assess. Rev. 41, 10-20 (2013).

35. Carles, J. L., Barrio, I. L. \& De Lucio, J. V. Sound influence on landscape values. Landsc. Urban Plan. 43, 191-200 (1999).

36. Maffei, L., Masullo, M., Aletta, F. \& Di Gabriele, M. The influence of visual characteristics of barriers on railway noise perception. Sci. Total Environ. 445-446, 41-47 (2013).

37. Echevarria Sanchez, G. M., Sun, K., De Coensel, B. \& Botteldooren, D. The relative importance of visual and sound design in the rehabilitation of a bridge connecting a highly populated area and a park. in Proceedings of InterNoise 2016 6810-6816 (InterNoise and NOISE-CON, 2016).

38. Van Renterghem, T. \& Botteldooren, D. View on outdoor vegetation reduces noise annoyance for dwellers near busy roads. Landsc. Urban Plan. 148, 203-215 (2016).

39. Gidlöf-Gunnarsson, A. \& Öhrström, E. Noise and well-being in urban residential environments: The potential role of perceived availability to nearby green areas. Landsc. Urban Plan. 83, 115-126 (2007).

40. Fyhri, A. \& Klæboe, R. Exploring the impact of visual aesthetics on the soundscape. in Proceedings of InterNoise 1999 (1999).

41. Langdon, F. J. Noise nuisance caused by road traffic in residential areas: Part III. J. Sound Vib. 49, 241-256 (1976).

42. Gidlöf-Gunnarsson, A. \& Öhrström, E. Attractive 'quiet' courtyards: A potential modifier of urban residents' responses to road traffic noise? Int. J. Environ. Res. Public Health 7, 3359-3375 (2010).

43. World Medical Organization. The Declaration of Helsinki. Bulletin of the World Health Organization (2013). doi:10.1001/jama.2013.281053

44. White, K. et al. Noise annoyance caused by continuous descent approaches compared to regular descent procedures. Appl. Acoust. 125, 194-198 (2017).

45. Arntzen, M. Aircraft noise calculation and synthesis in a non-standard atmosphere. (TU Delft, 2014).

46. Lethwory, N., Aalmoes, R. \& Miltenburg, M. Perception and Presence in Virtual Reality for Simulated Aircraft Noise. in Proceedings of InterNoise 2018 (2018).

47. Aalmoest, R., den Boer, M. \& Veerbeek, H. Virtual Reality Aircraft Noise Simulation for Community Engagement. in Proceedings of Internoise 2018 (2018).

48. Jeon, J. Y., Lee, P. J., You, J. \& Kang, J. Perceptual assessment of quality of urban soundscapes with combined noise sources and water sounds. J. Acoust. Soc. Am. 127, 1357-1366 (2010).

49. Maffei, L. et al. The effects of vision-related aspects on noise perception of wind turbines in quiet areas. Int. J. Environ. Res. Public Health 10, 1681-1697 (2013).

50. Masullo, M. \& Pascale, A. Effects of combination of water sounds and visual elements on the traffic noise mitigation in urban green parks. in Proceedings of InterNoise 2016 3910-3915 (InterNoise and NOISE-CON, 2016).

51. Axelsson, Ö., Nilsson, M. E. \& Berglund, B. A principal components model of soundscape perception. J. Acoust. Soc. Am. 128, 2836-2846 (2010).

52. de Coensel, B., Vanwetswinkel, S. \& Botteldooren, D. Effects of natural sounds on the perception of road traffic noise. J. Acoust. Soc. Am. 129, EL148-EL153 (2011).

53. Steele, D. et al. A comparison of soundscape evaluation methods in a large urban park in Montreal. in Proceedings of the 22th International Congress on Acoustics (ICA, 2016).

54. Weinfurt, K. Repeated measures analyses: ANOVA, MANOVA and HLM. in Reading and understanding more multivariate statistics (eds. Grimm, L. \& Yarnold, P.) (2008).

55. White, K., Bronkhorst, A. W. \& Meeter, M. Annoyance by transportation noise: The effects of source identity and tonal components. J. Acoust. Soc. Am. (2017). doi:10.1121/1.4982921

56. Zimmer, K., Ghani, J. \& Ellermeier, W. The role of task interference and exposure duration in judging noise annoyance. J. Sound Vib. 311, 1039-1051 (2008).

57. Yarnold, P. UniODA vs Bowker's Test for Symmertry: region of residence and time. Optimal Data Analysis 29-31 (2015). Available at: http://optimalprediction.com/files/pdf/V4A9.pdf. (Accessed: 25th September 2018)

58. Fagerland, M., Lydersen, S. \& Laake, P. Statistical Analysis of Contingency Tables. (Chapman \& Hall/CRC, 1974).

59. Guski, R. Personal and social variables as co-determinants of noise annoyance. Noise Heal. 1, 45-56 (1999).

60. de Coensel, B. \& Botteldooren, D. A model of saliency-based auditory attention to environmental sound. 20th Int. Congr. Acoust. ICA 2010 1-8 (2010).

61. Oldoni, D. et al. A computational model of auditory attention for use in soundscape research. J. Acoust. Soc. Am. 134, 852-861 (2013). 